The Egyptian Journal of Hospital Medicine (October 2019) Vol. 77 (5), Page 5597-5610

\title{
Comparative Study between Circum-areolar Skin Reduction and Standard Long Scar Techniques for Treatment of Severe Degrees of Gynaecomastia after Massive Weight Loss
}

\author{
Ismael Mahmoud Selim, Fawzy Ahmad Hamza, Mustafa Sayed Ahmed Meky \\ Plastic and Burn surgery Department, Faculty of Medicine, Al-Azhar University, Cairo, Egypt. \\ *Corresponding author: Ismael Mahmoud Selim, E-mail: ismaelshtya@ azhar.edu.eg
}

\begin{abstract}
Background: Reshaping of the male chest following massive weight loss is challenging and there are many techniques for its management.

Aim: This study was to compare circum-areolar skin reduction for the treatment of severe gynaecomastia in massive weight loss patients with other standard long scar techniques.

Patients and methods: Patients with massive weight loss whom their redundant and ptosed breast and patients whom their weight was stable for at least 6 months before surgical intervention for the treatment of gynaecomastia. Those patients were included in the study. Patients were subjected to either circum-areolar or other long standard scar techniques in 2 equal groups. Patients were evaluated subjectively and objectively.

Results: As for patient's satisfaction, there was statistically significant higher satisfaction $(\mathrm{p}=0.039)$ among patients submitted to circum-areolar approach regarding the overall chest contour (80\% vs 50\%) and nipple-areola complex aesthetics (90\% vs 60\%). Objective assessment showed better outcome for circum-areolar scar in cases of moderate skin laxity and minimal glandular tissue, while other long standard scars could be appropriate with patients having massive skin laxity and marked glandular atrophy.

Conclusion: Circum-areolar skin reduction technique is an effective, safe, and promising approach in the management of gynaecomastia after massive weight loss, which is an accomplished advancement relative to other standard long scar techniques. Circum-areolar skin reduction technique is the best for the patients with moderate skin redundancy where it preserved glandular tissue and no presence of side or back rolls. While, long scar techniques are favorable in patients with severe skin redundancy and atrophied glandular tissue with side or back rolls.
\end{abstract}

Keywords: Severe Gynaecomastia, Massive Weight Loss, Circum-areolar Approach, Inferior Pedicle Approach.

\section{INTRODUCTION}

The Romer and Pelizaeus Museum of Hildesheim, Germany, hosts a large collection of Ancient Egyptian artworks, one of the most remarkable of which is the sculpture of Hemiunu (fl.2570 BC) the architect of the Great Pyramid of Giza, Egypt. Hemiunu was a leading political figure of his time who served as vizier (minister). In this statue, discovered in 1912 in a monumental tomb in Giza, close to the pyramids, Hemiunu represented with marked gynecomastia ${ }^{(1)}$ (Figure 1). 


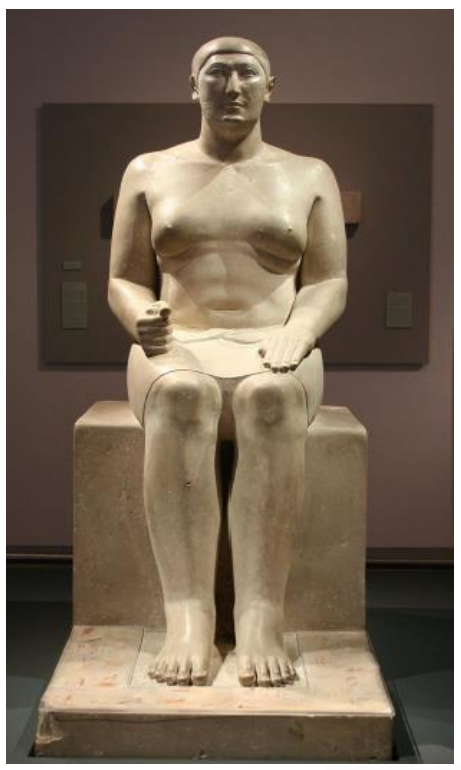

Figure (1): Limestone statue of Hemiunu, Roemerund Pelizaeus-Museum Hildesheim, Hildesheim, Germany.

Later in the Islamic Golden Age, Abul Qassim al-Zahrawi, known as Abulcasis, a well-known Andalusian Muslim surgeon which was born in al-Zahra (near Cordoba, Spain) in 936 AD. Al-Zahrawi described in his book Kitab al-Tasrif Leman Ajiz an alTaalif two dierent surgical techniques for the treatment of gynecomastia. The first technique included making a lunate incision above the breast and removal of the subcutaneous fat. The second surgical technique involved making two lunate incisions along the upper part of the breast to allow the removal of subcutaneous fat as well as redundant skin ${ }^{(2)}$ (Figure 2).
Patients who achieved weight loss with residual gynecomastia are highly demanding patients. In Egypt, there were seasonal demands for gynecomastia as some of these patients need to enhance the shape of their breasts for applying to military and police academies. Others feel so ashamed hiding their bodies in loose clothes especially in public gathering, during exercise and on the beach which could be described as body dysmorphic disorder ${ }^{(3)}$. Reshaping of the male chest following massive weight loss is challenging because of severe tissue ptosis that often renders standard surgical techniques with extensive scarring undesirable from an aesthetic outcome point of view and also has the same patient concerns of pre-weight loss breast shape (Braunstein, 2007).
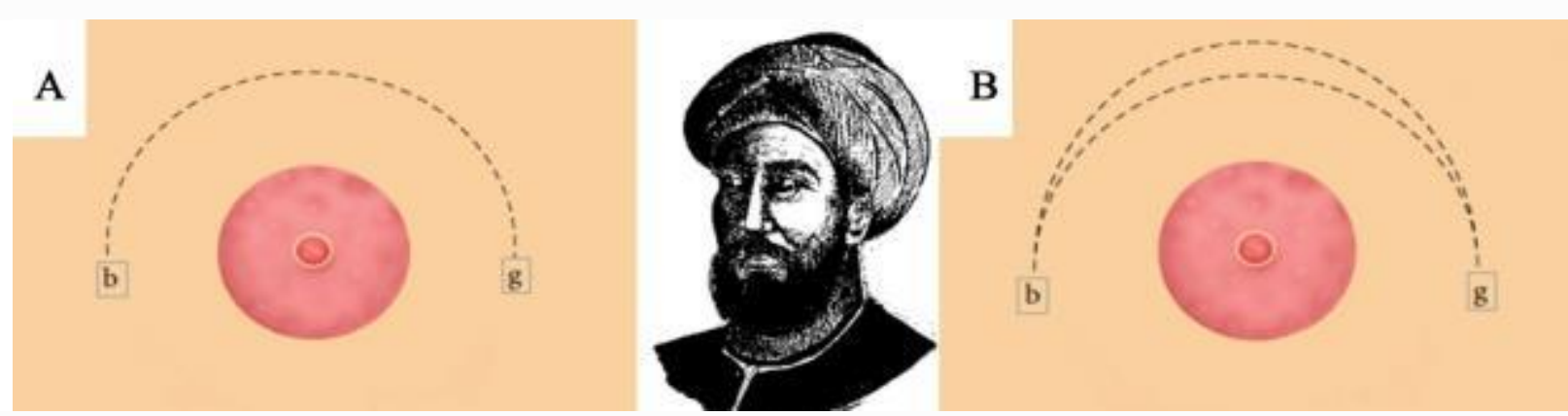

Figure (2): According to Al-Zahrawi, A. Surgical treatment of moderate gynecomastia (A lunate incision is made above the breast and the subcutaneous fat is removed). B. Surgical treatment of severe gynecomastia (Two lunate 
incisions are made along the upper part of the breast to allow the removal of subcutaneous fat along with the excess skin).

To shed light in this issue, this study has been conducted to compare circum-areolar skin reduction for the treatment of severe gynaecomastia in massive weight loss patients in comparison with other standard long scar techniques.

Aim of the work: This study was to compare circum-areolar skin reduction for the treatment of severe gynaecomastia in massive weight loss patients with other standard long scar techniques.

\section{PATIENTS AND METHODS}

\section{Study design:}

This study is a prospective non-randomized interventional study, consisted of 20 men, aged from 20 to 35 years old who were subjected for correction of severe gynecomastia and severe ptosis of the male breast after massive weight loss. 7 of them were grade IIb and 13 were grade III according to Simon's classification. The study was conducted between January 2019 and June 2019. This study has been executed at the Plastic Surgery Department, AlHussien and Sayed Galal University Hospitals, Faculty of Medicine, Al-Azhar University, Cairo, Egypt.

\section{Inclusion Criteria:}

- Patients with massive weight loss who lost $50 \%$ or more of their excess weight.

- Patients who their weights were stable for at least 6 months before surgery.

- Patients with bilateral gynecomastia.

\section{Exclusion Criteria:}

- Patients refused to enroll in the study,

- Patients with ongoing weight loss,

- Heavy smoker patients,

- Patients with co-morbid health problems.

- Patients with unilateral gynecomastia.
- Patients with secondary gynecomastia.

\section{Ethical approval:}

An approved was obtained from the Ethical Research Board (ERB) of the Faculty of Medicine, Al-Azhar University, Cairo, Egypt. Prior to study proceeding, all patients assigned informed consents after the obvious explanation of the possible adverse events, and the potential risks of the surgical intervention.

\section{Parameters of Assessment:}

- Patients were exposed to subjective and objective assessment protocol of results.

- Subjective assessment was done through a questionnaire given to every patient including their satisfaction with the overall results, their acceptance to final scars in comparison with other kinds of scars, their breast and chest contour.

- An objective assessment was done through a questionnaire given to the members of the Plastic Surgery Department, Al-Azhar University during the scientific meeting asking about the overall results of randomly selected patients from the 2 groups.

- The Questionnaire included final shape of the breast, the success in removing all the excess breast tissue, scar quality, equality, breast contour, residual ptosis, improvement of lateral chest wall rolls, longstanding re-ptosis and NAC symmetry.

- Aesthetic landmarks of the chest were assessed by asking the members of plastic surgery department to rate the overall chest contour and nipple-areola complex aesthetics on a three categories low, moderate and high satisfaction.

- Based on three grades of satisfaction, patients were asked: "how would you rate your overall chest contour" and "your nipple areola complex". Patients were then asked several yes or no questions: "would you 
recommend it to a friend," "go shirtless in public," "do you have nipple sensitivity," and "do you have strange feelings in the nipple, like burning or shooting pains"?

\section{Pre-operative evaluation:}

Prior to surgical intervention, all participants were subjected to history taking and clinical evaluation to reveal their age, onset of gynecomastia, duration of symptoms, prebody contouring surgery, post-weight loss weight, height, body mass index (BMI), chest circumference, grade of gynecomastia, skin quality, associated co-morbidities (smoking, hypertension, renal dysfunction, liver dysfunction, cardiovascular insufficiency, endocrine diseases, and metabolic syndrome), previous operative related complications such as wound infection, wound dehiscence, hematoma, and scars.
All patients were photographed preoperatively to form a classification scheme-based on severity of gynecomastia. Colored photos included frontal, left oblique, right oblique, left lateral and right lateral views. Routine investigations were done prior to surgery for anesthetic purpose and to exclude secondary causes. Markings were done pre-operatively while standing, All Procedures were done under general anesthesia with local infiltration of tumescent solution in two planes (Sub-cutaneous and Retro-glandular).

\section{Surgical procedures:}

Patients were classified into 2 groups according to the procedure implemented either circum-areolar or other long standard technique.

\section{Group A:}

* Circum-areolar skin reduction - Doughnut Technique - (10 Cases):

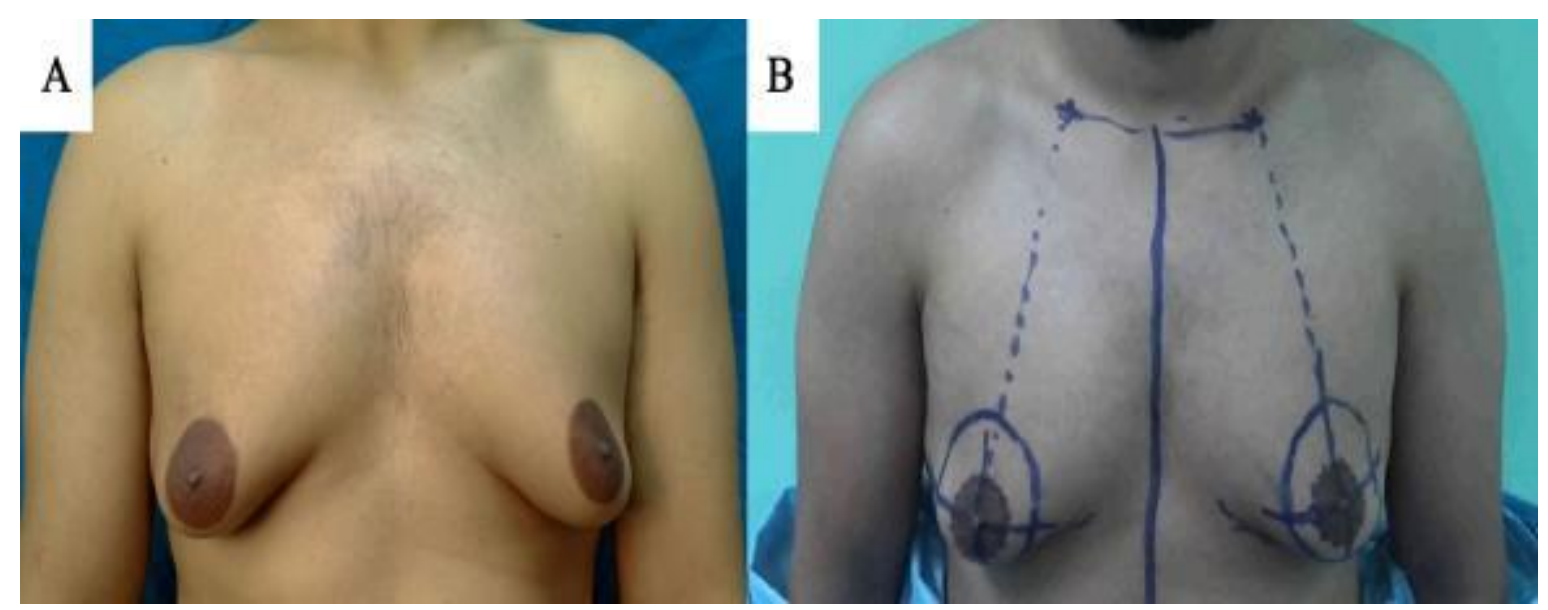

Figure (3): Patient. 1 A. Preoperative AP view, B. Markings.

10 patients were selected randomly noting the degree of sagging and the elasticity of the skin to help determining the size and thickness of the fibrous gynecomastia and the surrounding fat using pinch test. The skin was marked preoperatively while the patient is in standing position (Figure 3). The border limits of the breast, especially the inframammary fold and the lateral excess, were determined. The mid-clavicular point was marked, and from this point a vertical line to the inframammary fold passing through the nipple was traced. The new areolar position was traced on this line at 16 to $18 \mathrm{~cm}$ from the mid-clavicular point. A circular peri-areolar mark was traced corresponding to the cutaneous excess that has to be removed according to the equation. 
$R=R^{\prime} \times(8 / 10)+R^{\prime}$, as $R$ is the radius of the outer circle and $R^{\prime}$ is the radius of $N$

Single intravenous dose of a broad-spectrum antibiotic was administered preoperatively according to sensitivity test. The patient was placed in supine position on the operating table with arms abducted on arm boards. Surgery was performed with the patient under general anesthesia. We started by infiltration of the breast tissue with a tumescent solution comprising of $500 \mathrm{~mL}$ of normal saline solution with $1 \mathrm{~mL}$ of 1:1000 adrenaline and $10 \mathrm{~mL}$ xylocaine. Generally, 300 to $400 \mathrm{~mL}$ of fluid was infiltrated subcutaneously into each breast in subareolar and retro-glandular planes for Hemostasis. The liposuction cannula was inserted through a 3-mm cutaneous incision made at the lower lateral angle of the marked area of the breast (site of drain insertion) in 4 patients, the other 6 patients was performed without liposuction.

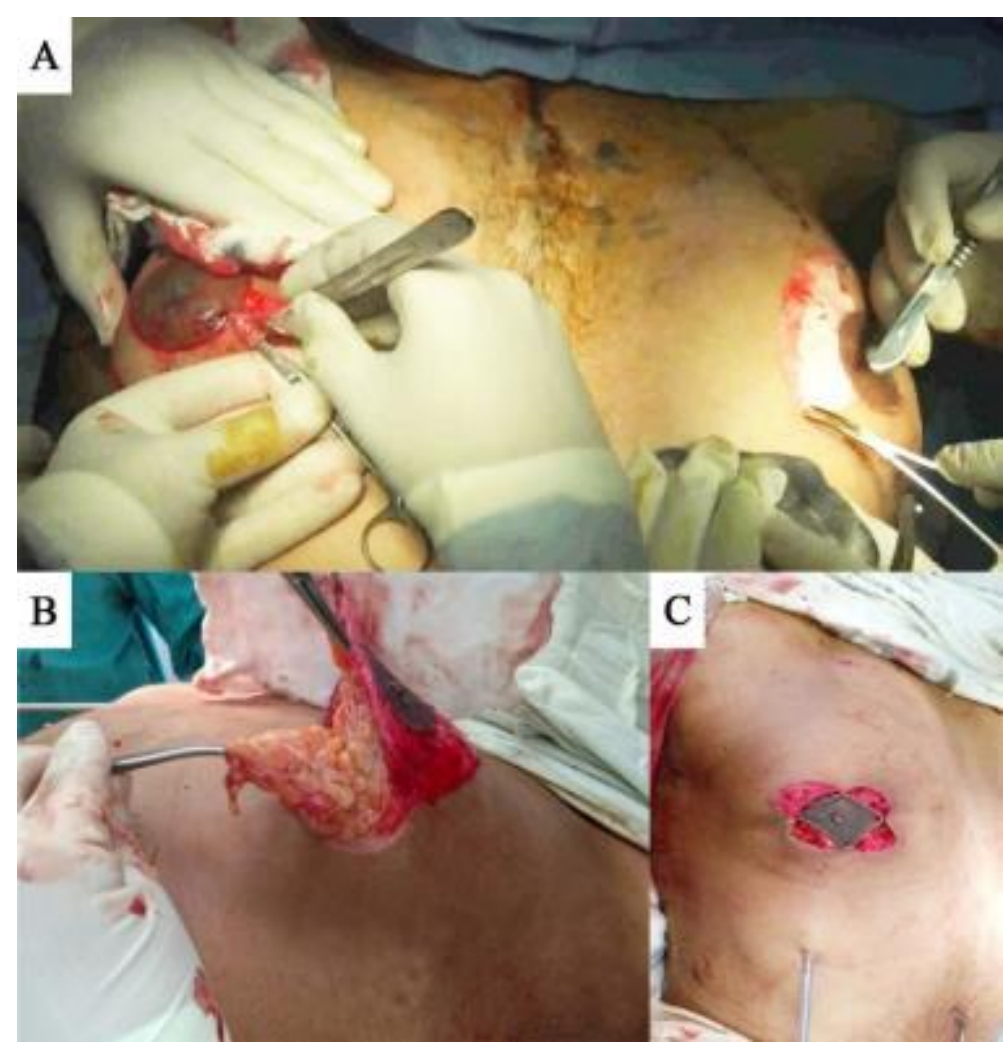

Figure (4): A. De-epithelization, B. Dissection in a plane just beneath the NAC flap, C. Closure of the peri-areolar incision at 3, 6, 9, 12 o'clock, then Closure by purse string sutures.

Initially, liposuction of adipose tissue on the periphery of the mammary region was performed to smoothen the contour and to release the infra-mammary fold. It was continued until losing of tissue resistance, notable reduction of the breast volume (assessed by pinch test), or bloody aspirate was observed. The skin between the outer and inner circles is de-epithelialized while avoiding any damage to the vascular flow of the nipple areolar complex. A superiorly based nipple areola complex flap was created by incising the lower half of the circumareolar region from 3 o'clock to 9 o'clock position. The thickness of the flap was $1 \mathrm{~cm}$ as we proceed downward to upward, the dissection would continue in a plane just beneath the nipple areolar complex flap and 
above the rest of the breast tissue. Then peeling the excess glandular tissue was done from the pectoralis fascia by both blunt and sharp dissection (Figure 4). Freeing the inframammary fold was done with both sharp dissection using scissor and blunt dissection using the liposuction cannula. Hemostasis with cautery and irrigating the pocket with saline garamycin and inspection for bleeding or any remaining lumps that need resection was done, followed by insertion of 16-French suction drain from the liposuction incision. The superior pedicle NAC flap was folded smoothly on itself by Benelli technique using
Vicryl 2/0 at 3, 6, 9, and 12 o'clock position followed by another 4 sutures in between the previous 4 sutures. The cutaneous periareolar incision was secured with simple interrupted or purse-string intradermal suture using Prolene 4/0. Then, a compressive dressing covering the operated region was applied and kept on for one week. Drains were removed three days in most cases, the corset was dressed for one and a half months and the sutures were removed after 3 weeks post-operatively. Outpatient follow-up was performed one week, two weeks and one, three, and six months after surgery (Figure 5).

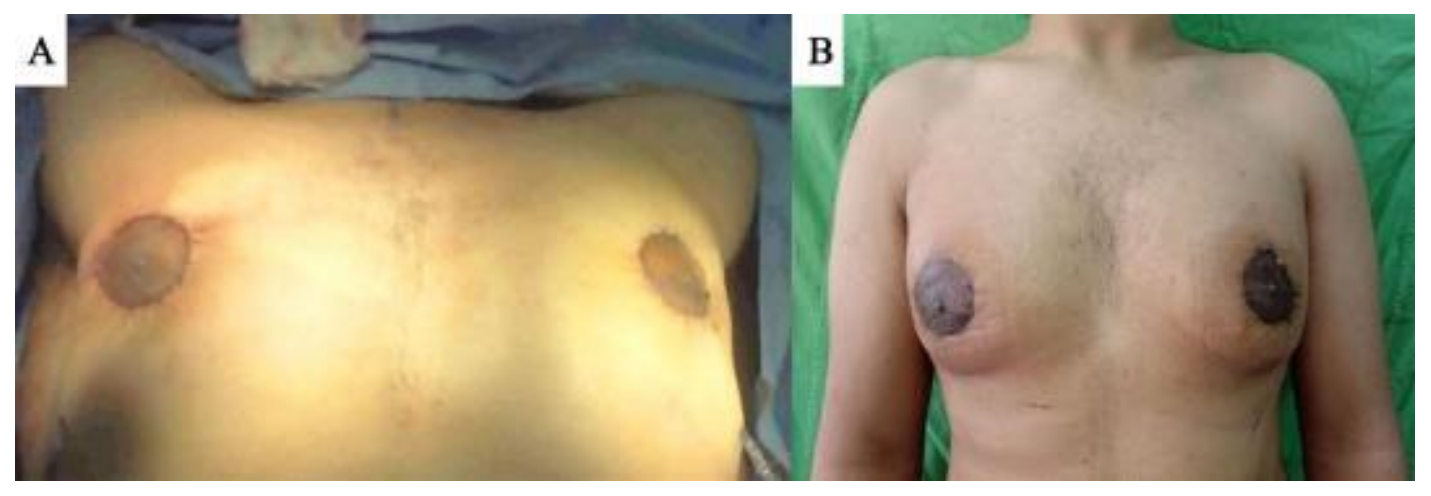

Figure (5): A. Immediate post-operatively, B. one month post operatively.

\section{Group B:}

The other 10 patients were selected randomly too and subjected to different long standard scar techniques breast reduction including

- Transvers Scar ( 6 cases)

- Inverted T Scar (2 Case)

- Boomerang Skin Reduction with J- Torsoplasty (1 Case)

- Lateral Wedge Skin Reduction (1 Case)

\section{Inferior Pedicle Skin Reduction with Transvers Scar (8 Cases):}

Drawing was performed preoperatively on standing position. The drawings delineated the palpable gland limits, with the inferior resection line being placed in the inframammary fold, and the amount of tissue to be resected determined by a pinch test (generally just above the areola) (Figure 6). 


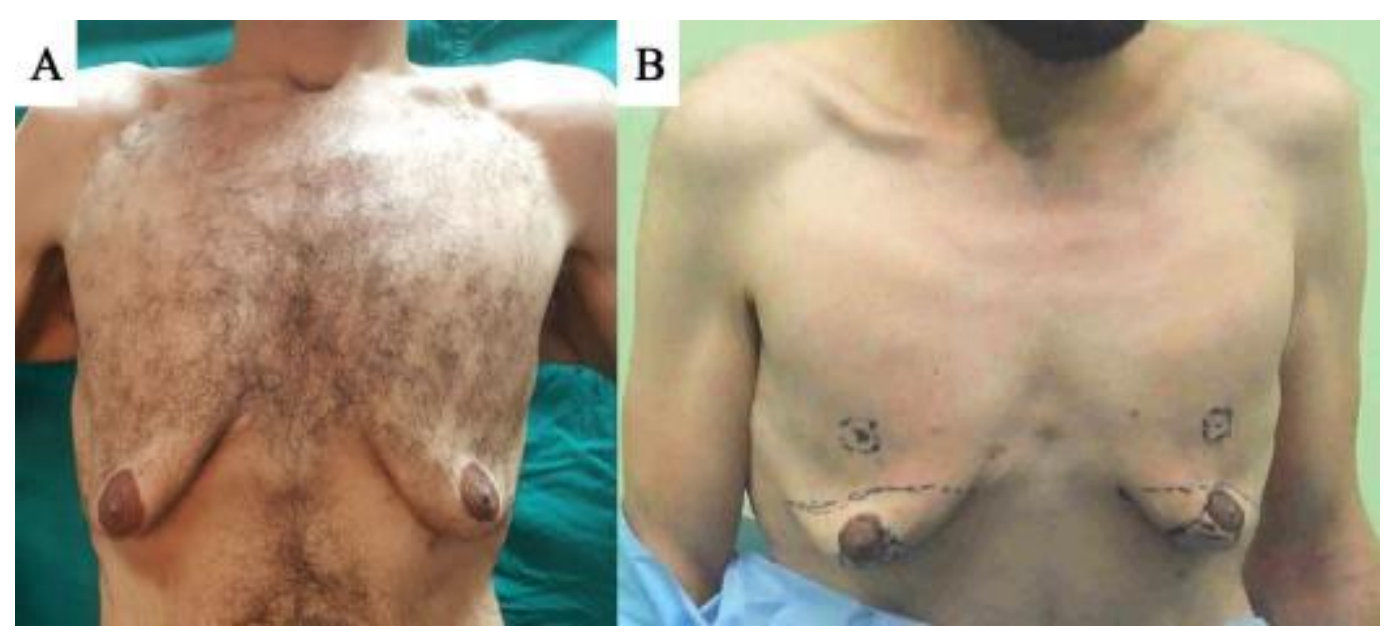

Figure (6): A. Pre-operative AP view, B. Markings.

We then determined the new location of the nipple areola complex $4 \mathrm{~cm}$ above the inframammary fold, the radius of the new NAC was drawn to be $2.5 \mathrm{~cm}$. This position corresponds generally to the mid-arm $24 \mathrm{~cm}$ from suprasternal notch or to the fourth intercostal space (Figure 7).
Surgery was performed under general anesthesia. The patient was placed in the supine position with the arms abducted at 90 degrees. A tumescent solution comprising of $500 \mathrm{~mL}$ of normal saline solution with $1 \mathrm{~mL}$ of 1:1000 adrenaline and $10 \mathrm{~mL}$ xylocaine was prepared. 300 to $400 \mathrm{~mL}$ of fluid was infiltrated subcutaneously into each breast.
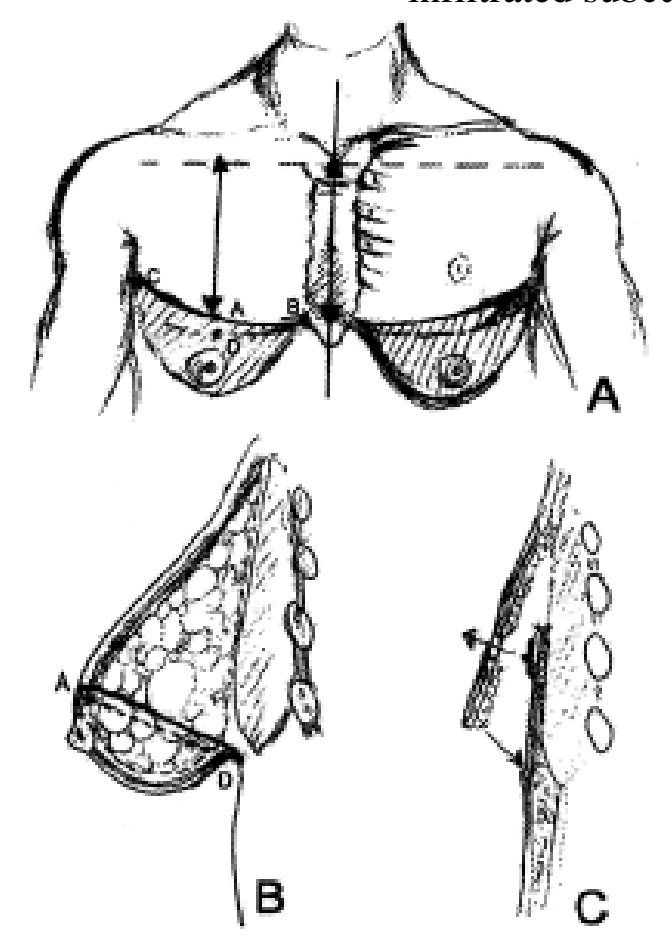

Figure (7): Diagrammatic illustration of the design of the technique, A. Anterior view, B. Lateral view, C. Tucking of the inferior flap under the upper one and exteriorization of the nipple ${ }^{(4)}$.

In most cases we started by liposuction of the entire thoracic area, except for the area of the pedicle using a 4-mm cannula. This procedure drastically removed deep and 
superficial fat from the infero-internal and infero-external quadrants, allowing all fat under the dermis of this area to be eliminated. At the superior quadrants, only deep fat was aspirated.De-epithelialization of the flap between the areola and inframammary fold was done. We checked the resection lines of the infero-internal and infero-external quadrants by pinching the skin, then incised along the tracks. Using electrocautery, we removed these quadrants close to the dermis.Dissection of the superior thoracic flap was done, at the upper extremity of the areolar flap. We did a bevel dissection to reduce the stair effect. This was then sutured to the pectoral fascia by absorbable stitches then we fixed the superior thoracic flap to the inframammary fold.

The new location of the NAC corresponded to the predetermined drawing on the superior thoracic flap. We then proceeded to perform the skin incision, remove a skin and fat cylinder on the superior thoracic flap. Finally, the nipple-areola complex was transpose using a technique similar to that employed to transpose an umbilicus in abdominoplasty (Figure 8). The NAC was then secured by eight subcutaneous reversing stitches with 3/0 absorbable Vicryl thread. Two suction drains were inserted, exiting at the inner and outer extensions of the inframammary scar.

A three-plane suture was done, Anchoring deep stitches with 0 Vicryl thread, subcutaneous inverted stitches with 3-0 Vicryl and intradermal sutures with 4-0 $\mathrm{n}$ Prolene thread. A compression bandage was applied and kept in place day and night for 1 week. Coreset was worn over a total period of 2 months. A sports exemption was also requested for 2 months (Figure 9)

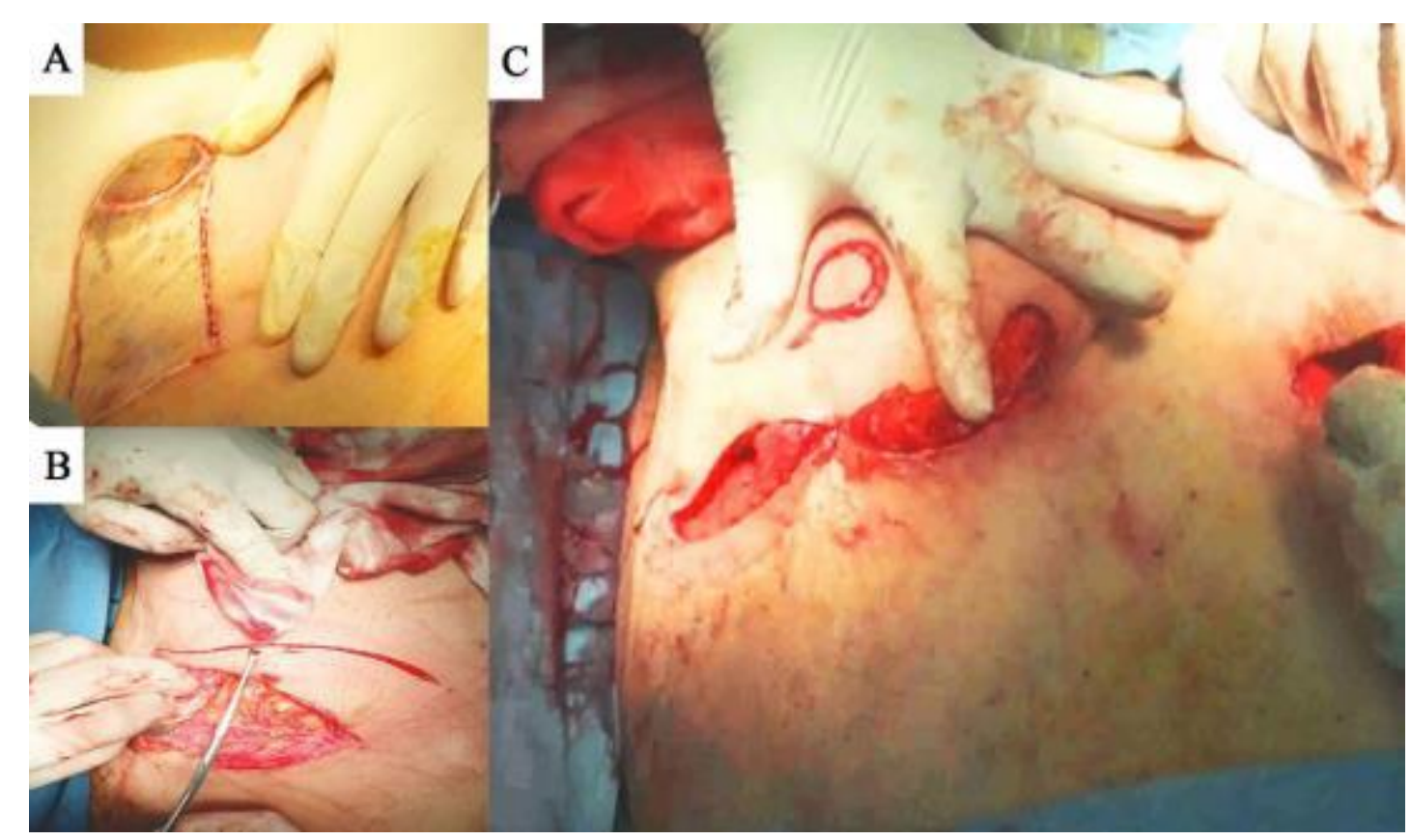

Figure (8): A. De-epithelialization of inferior Pedicle, B. Removal of outlined excess skin, C.Fixation of the superior thoracic flap to the inframammary fold and transposition of the NAC. 


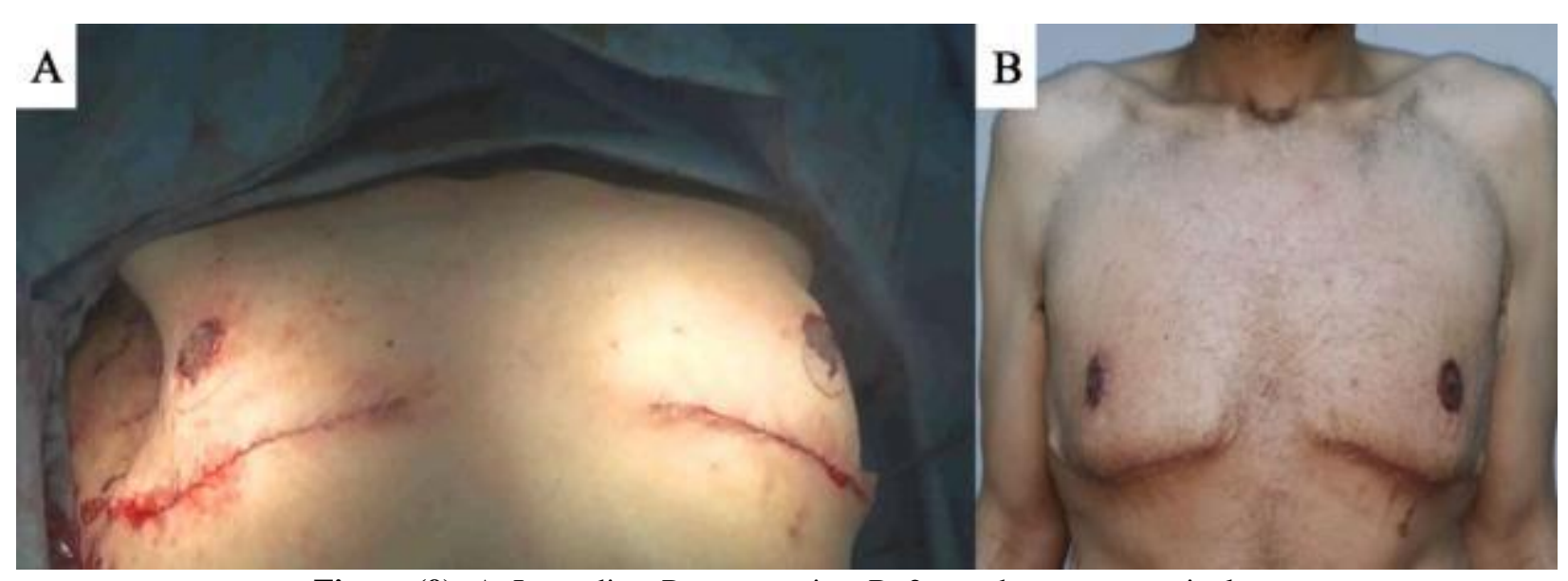

Figure (9): A. Immediate Post-operative, B. 2 months post-operatively.

\section{Post-operative evaluation:}

Analgesia, antibiotics and anti-edematous treatment were given to all patients. For each follow-up visit, all candidates were submitted to a review clinical evaluation including a rating of chest and nipple-areolar complex aesthetics.

Close follow-up protocol was done for early detection of complications. In contrast, patients developed wound infection were treated by frequent dressings. Whereas patients experienced hematoma were treated by revision and hemostasis. Patients developed seroma were subjected to frequent aspiration. In addition, patients experienced hypertrophic scars and keloid were treated using topical anti-scar agents for 2 months then multipole Laser sessions.

\section{RESULTS}

\section{Patient's demographic characteristics}

An overall 20 patients who fulfilled the inclusion criteria were enrolled in the current study. Of them, 10 patients were subjected to circum-areolar skin reduction approach and the other 10 patients were managed by long scar techniques ( 7 patients to Inferior pedicle with transverse scar, one patient to wise pattern technique with inverted-T scar, one patient to Boomerang technique with $\mathrm{J}$ torsoplasty and one patient to lateral wedge technique). The mean age of the included patients was $27.4 \pm 3.8$ years and $27.2 \pm 4.34$ years among G1 and G2, respectively. $(p=0.939)$. There was an equal proportion of smokers (3 patients) among both groups. There was no statistically significant difference between both groups regarding pre-massive weight loss weight $(\mathrm{p}=0.64)$, post-massive weight loss weight $(\mathrm{p}=0.98)$, post-massive weight loss BMI $(\mathrm{p}=0.79)$ and height $(\mathrm{p}=0.67)$. There were three and four patients subjected to previous bariatric surgery among G1 and G2, respectively $(\mathrm{p}=0.63)($ Table $1 \& 2)$. 
Table (1): Patients demographic characteristics

\begin{tabular}{|c|c|c|c|c|}
\hline \multirow[b]{2}{*}{ Variable } & G1 & G2 & \multirow{2}{*}{\multicolumn{2}{|c|}{ P-Value }} \\
\hline & $\begin{array}{l}\text { Mean } \\
(\mathrm{SD}) / \\
\mathrm{N}(\%)\end{array}$ & $\begin{array}{c}\text { Mean } \\
\text { (SD)/ N } \\
(\%)\end{array}$ & & \\
\hline Age & $\begin{array}{c}27.4 \pm \\
3.8\end{array}$ & $\begin{array}{c}27.2 \pm \\
4.34\end{array}$ & \multicolumn{2}{|c|}{0.939} \\
\hline \multicolumn{5}{|c|}{ Co-Morbidities } \\
\hline Smoking & $(30 \%)$ & $(30 \%)$ & & 1 \\
\hline \multicolumn{2}{|l|}{ Hypertension } & 0 & 0 & $\ldots$ \\
\hline \multicolumn{2}{|l|}{ Endocrine disease } & 0 & 0 & \\
\hline \multirow{2}{*}{\multicolumn{2}{|c|}{$\begin{array}{l}\text { Liver dysfunction } \\
\text { Renal impairment }\end{array}$}} & 0 & 0 & \\
\hline \multirow{2}{*}{\multicolumn{2}{|c|}{$\begin{array}{l}\text { Renal impairment } \\
\text { Diabetes }\end{array}$}} & 0 & 0 & \\
\hline & & 0 & 0 & \\
\hline \multicolumn{2}{|l|}{$\begin{array}{c}\text { Diabetes } \\
\text { History of medications }\end{array}$} & 0 & 0 & \\
\hline
\end{tabular}

Table (2): Demographic characteristics of the patients with the time of massive weight loss.

\begin{tabular}{|c|c|c|c|}
\hline Variables & G1 & G2 & P-Value \\
\cline { 2 - 3 } & Mean (SD)/ N (\%) & Mean (SD)/ N (\%) & 0.64 \\
\hline $\begin{array}{c}\text { Pre-massive weight loss } \\
\text { weight }\end{array}$ & $127.3 \pm 14.5$ & $130.4 \pm 14.2$ & 0.98 \\
\hline $\begin{array}{c}\text { Post- massive weight loss } \\
\text { weight }\end{array}$ & $88 \pm 8.9$ & $88.06 \pm 6.02$ & 0.79 \\
\hline $\begin{array}{c}\text { Pre- massive weight loss } \\
\text { BMI }\end{array}$ & $174.9 \pm 8.3$ & $176 \pm 9.33$ & 0.67 \\
\hline $\begin{array}{c}\text { Pre- massive weight loss } \\
\text { Height }\end{array}$ & $32.8 \pm 3.9$ & $31.2 \pm 3.6$ & 0.63 \\
\hline Previous Bariatric surgery & $3(30 \%)$ & $4(40 \%)$ & \\
\hline
\end{tabular}

* G2 $\rightarrow$ Other Long Standard Techniques Group.

Post-operative outcomes

Regarding post-operative complications, there was no statistically significant difference between patients of G1 and G2. However, patients of $\mathrm{G} 2$ experienced higher post-operative complications in the terms of wound infection (20\% vs $30 \%)$, and altered nipple sensation ( $10 \%$ vs $20 \%$ ). There was no difference regarding keloid (10\% vs $10 \%)$, hematoma (10\% vs $10 \%)$ and residual asymmetry (10\% vs $10 \%)$. On the contrary, patients of G1 experienced more postoperative complications relative to those of G2 in seroma (20\% vs $10 \%)$ and wound dehiscence (20\% vs 10\%)(Figure 10). 


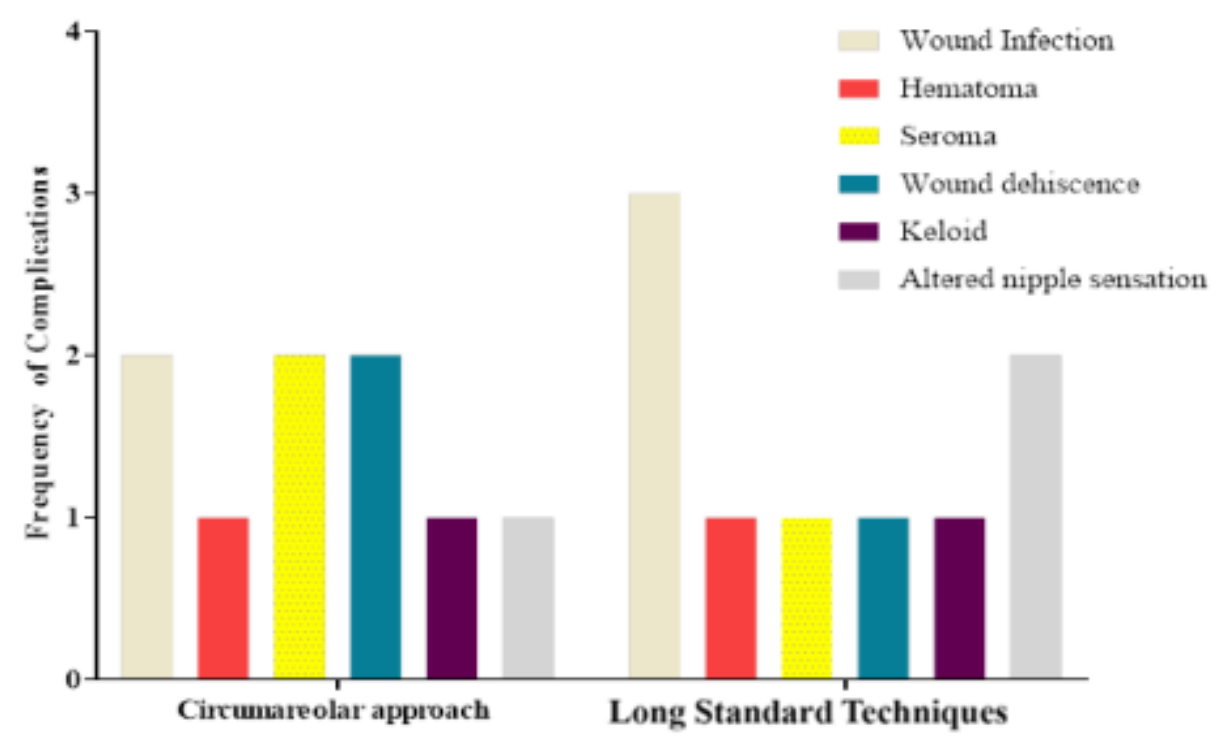

Figure (10): Bar chart showed the pattern of complications among the studied groups

\begin{tabular}{|c|c|c|c|}
\hline \multirow{2}{*}{ Table(3): Surgeons evaluation of the aesthetic outcomes } \\
\hline Variable & G1 & G2 & P-Value \\
\hline \multicolumn{4}{|c|}{ The overall chest contour } \\
\hline High satisfaction & $6(60 \%)$ & $4(40 \%)$ & 0.064 \\
\hline Moderate satisfaction & $3(30 \%)$ & $2(20 \%)$ & 0.51 \\
\hline Low satisfaction & $1(10 \%)$ & $2(20 \%)$ & 0.81 \\
\hline \multicolumn{4}{|c|}{ Nipple-areola complex aesthetics } \\
\hline High satisfaction & $7(70 \%)$ & $5(50 \%)$ & 0.076 \\
\hline Moderate satisfaction & $2(20 \%)$ & $1(10 \%)$ & 0.81 \\
\hline Low satisfaction & $1(10 \%)$ & $2(20 \%)$ & 0.81 \\
\hline
\end{tabular}

between both groups regarding surgeon's satisfaction (Table 3).

As for the surgeon's satisfaction, they were highly satisfied from $60 \%$ and $40 \%$ of the patients among $\mathrm{G} 1$ and $\mathrm{G} 2$, respectively, regarding the overall chest contour. Regarding nipple-areola complex aesthetics, surgeons were highly satisfied from $70 \%$ of patients of $\mathrm{G} 1$ and $50 \%$ of patients of $\mathrm{G} 2$. There was no statically significant difference

As for patient's satisfaction, there was statically significant higher satisfaction $(\mathrm{p}=0.039)$ among $\mathrm{G} 1$ than $\mathrm{G} 2$ regarding the overall chest contour (80\% vs $50 \%)$, respectively. Similar to that, there was a statically significant higher satisfaction $(p=0.002)$ among patients of G1 relative to 
G2 (90\% vs 60\%), respectively, regarding the nipple-areola complex aesthetics (Table 4).

Table.4 Patients evaluation of the aesthetic outcomes.

\begin{tabular}{|c|c|c|c|}
\hline Variable & G1 & G2 & P-Value \\
\hline \multicolumn{3}{|c|}{ The overall chest contour } \\
\hline High satisfaction & $8(80 \%)$ & $5(50 \%)$ & 0.039 \\
\hline Moderate satisfaction & $1(10 \%)$ & $1(10 \%)$ & 1 \\
\hline Low satisfaction & $1(10 \%)$ & $2(20 \%)$ & 0.97 \\
\hline \multicolumn{4}{|c|}{ Nipple-areola complex aesthetics } \\
\hline High satisfaction & $9(90 \%)$ & $6(60 \%)$ & 0.02 \\
\hline Moderate satisfaction & $1(10 \%)$ & 0 & \\
\hline Low satisfaction & 0 & $2(20 \%)$ & \\
\hline
\end{tabular}

Based on the above results and our clinical observations, the study proposes a modified Simon's classification for treatment of gynecomastia after MWL based on aesthetic outcomes as the following: Patients with moderate skin redundancy and minimal glandular atrophy mainly post MWL by diet could be managed by circum-areolar skin reduction technique. While others with massive skin redundancy, marked glandular atrophy mainly post MWL and post-bariatric surgery could be managed by other long standard techniques.

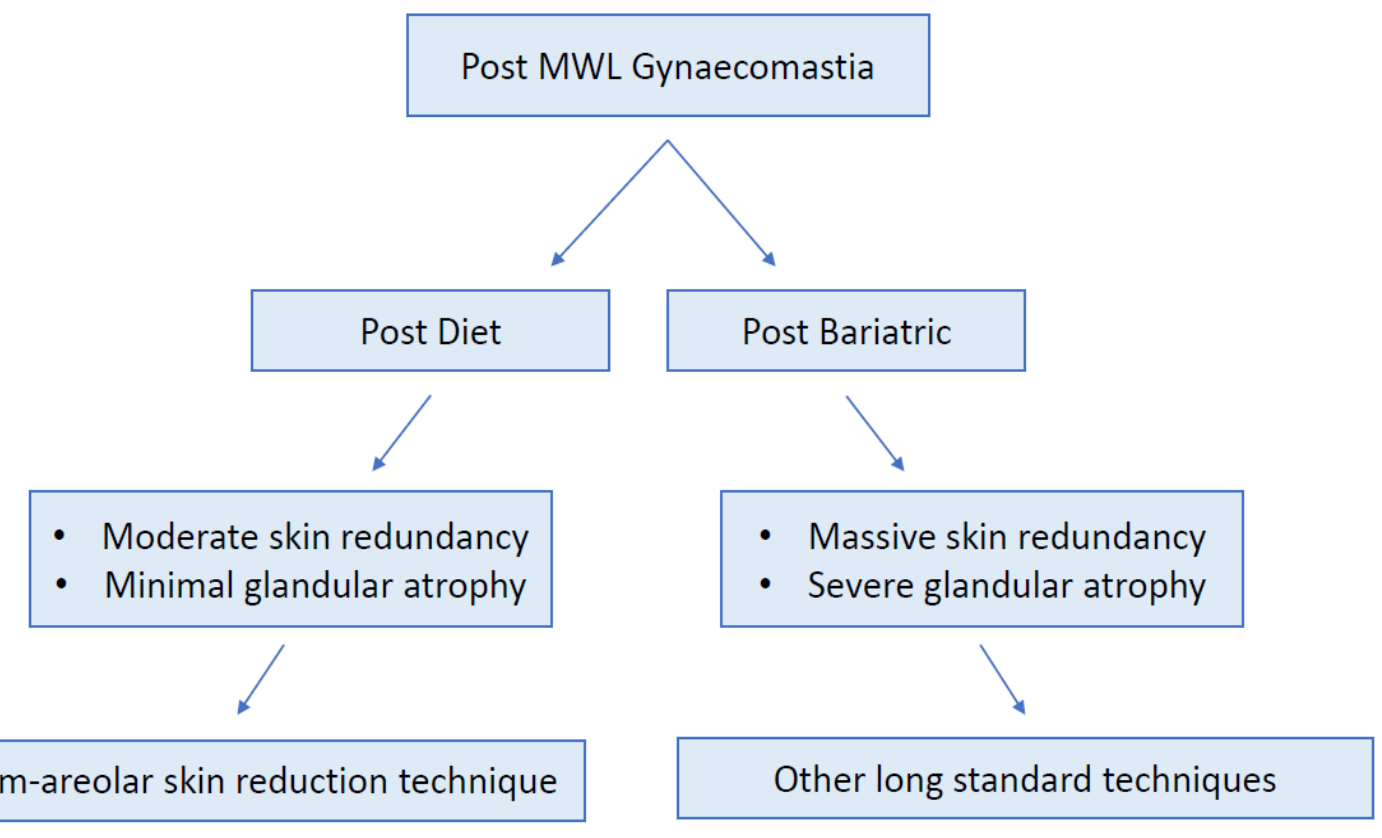

Figure (11): shows proposed classification for gynecomastia in post MWL and its management ${ }^{(\mathbf{3})}$. 


\section{DISCUSSION}

The number of gynecomastia cases increased by 22 percent from 2005 to 2006 . A common deformity seen in the male population is an excess in redundant skin of the chest wall. The development of effective bariatric surgical techniques to manage morbid obesity led to a demand for surgical restoration of body morphology through surgical management ${ }^{(5)}$. Patients have great expectations of a marked improvement of their degraded self-image for which they have often been ill-prepared prior to bariatric surgery ${ }^{(6)}$.

In this respect, Jay and Segwapa ${ }^{(7)}$ notified that patients received circum-areolar approach accomplished the desired cosmetic appearance of the NAC and chest at 6-months follow-up and at 1-year follow-up. Additionally, all participants were satisfied from the final appearance of the scar. Moreover, Persichetti et al. ${ }^{(8)}$ believed that the complete circum-areolar technique, using a purse-string suture, creates the best esthetic results with fewer complications in patients with mild or moderate ptotic glandular breast enlargement with skin redundancy and areolar enlargement, but it was not valid for severely ptotic male breasts.

The present study brought to light that circum-areolar approach had the superiority in the management of gynecomastia after MWL in the terms of estimated blood loss and operation time along with Low NAC radius, low post-operative hospital stay and time to first ambulation relative to other long scar techniques. Additionally, patients subjected to circum-areolar approach accomplished better cosmetic outcomes regarding the overall chest contour and nipple-areola aesthetics. In the current study, two patients subordinated to circum-areolar approach and developed uncomplicated seromas postoperatively, and this underscores the importance of using a pressure bandage for one month over the chest postoperatively, as well as limiting excessive movement or exercise for six weeks postoperatively. Subsequently, two patients experienced wound infection. Whereby two and one patients had wound dehiscence and hematoma, respectively. In accordance with our results, Ibrahim et al. ${ }^{(9)}$ notified that after follow-up ranged from 3 months to 4 years, 8 complications were presented as follows: 1 hematoma, 1 wound dehiscence, 2 cases of hypertrophied scars, and 3 minor aesthetic problems near the areolae. Magdy ${ }^{(4)}$ notified that, among 24 operated breasts by inferior pedicle with no vertical scar technique, all patients healed nicely with no infection, disruption or seroma formation, though no drainage was used in any case. Symmetry was excellent regarding breast contour, nipple areola position and size. There were no residual breast tissues, skin redundancy, saucer deformity or delayed enlargement of the areolae. All patients were satisfied by the results. Most of the scars were accepted by the patients regarding site, size and quality. Only one patient developed hypertrophic scars and another had asymmetry of the scar level. This was because, such technique combines the benefit of extensive skin and glandular excision in massive forms maintaining excellent vascularity of the nipple areola complex with acceptable limited scars. Additionally, The absence of tension or points of meeting of flaps, as in the inverted $\mathrm{T}$ scar, makes the process of scare healing smooth and nice ${ }^{(10)}$.

Taken altogether, the surgical technique must be adapted to the type of deformity and existing anterior chest wall asymmetries. Allowances must be made for the amount of redundant skin. It must be kept in mind that the thorax has anterior and posterior midline 
zones of adherence that prevent their overlying skin from movement during weight gain and weight loss.

Despite the evidence summarized in the current investigation, some limitations may hinder the obtained evidence. The relatively small sample size which limited our ability to generalize our results. The short-follow up period which limited our ability to assess the long-term outcomes. The lack of randomization which led to unavoidable selection bias. Thereafter, large randomized controlled trials are mandatory to tackle the limitations of the current study.

\section{CONCLUSION}

Circum-areolar skin reduction technique is an effective, safe, and promising approach in the management of gynecomastia after massive weight loss, which accomplished advancement relative to inferior pedicle, Boomerang with J-torsoplasty and Lateral wedge techniques. for patients with moderate skin redundancy, preserved glandular tissue and no presence of side or back rolls. While other techniques are favorable in patients with severe skin redundancy, atrophied glandular tissue with side or back rolls.

\section{FINANCIAL SUPPORT AND SPONSORSHIP}

Nil.

\section{CONFLICTS OF INTEREST}

There are no conflicts of interest.

\section{REFERENCES}

1. Oranges $\mathrm{C}$, Wang W, Tremp $M$ et al. (2017): Gynecomastia in the Ancient Egypt limestone statue of Hemiunu, the architect of the Great Pyramid of Giza (fl. 2570 BC). Journal of Endocrinological Investigation, 40 (3): 337-338.
2. Chavoushi SH, Ghabili K, Kazemi A et al. (2012): Surgery for Gynecomastia in the Islamic Golden Age: Al-Tasrif of Al-Zahrawi (936-1013 http://dx.doi.org/10.5402/2012/934965 AD).

3. Mufaddel A, Ossama T. Osman, Almugaddam F et al. (2013): A Review of Body Dysmorphic Disorder and Its Presentation in Different Clinical Settings. Prim Care Companion CNS Disord., 15 (4): 12-14.

4. Magdy A (2008): A Limited Scar Approach to Massive Gynecomastia. Egypt J Plast Reconstr Surg., 32: 229-35.

5. Monpellier VM, Antoniou EE, Mulkens $S$ et al. (2019): Body Contouring Surgery after Massive Weight Loss: Excess Skin, Body Satisfaction, and Qualification for Reimbursement in a Dutch Post-Bariatric Surgery Population. Plastic and Reconstructive Surgery, 143 (5):1353-60.

6. Krauss S, Medesan R, Black J et al. (2019): Outcome of Body-Contouring Procedures After Massive Weight Loss. Obesity Surgery, 29 (6): 1832-40.

7. Jay T, Segwapa K (2017): The circumareolar approach to gynecomastia and transgender surgery: modifications to provide correct nipple areolar complex position and shape. South African Journal of Surgery, 55 (1): 16-20.

8. Persichetti P, Berloco M, Casadei RM et al. (2001): Gynecomastia and the complete circumareolar approach in the surgical management of skin redundancy. Plastic and Reconstructive Surgery, 107 (4): 948-54.

9. Ibrahiem SMS (2016): Severe gynecomastia: new technique using superior pedicle NAC flap through a circumareolar approach. Annals of Plastic Surgery, 76 (6): 645-51.

10. Costanzo PR, Pacenza NA, Aszpis SM et al. (2018): Clinical and Etiological Aspects of Gynecomastia in Adult Males: A Multicenter Study. https://doi.org/10.1155/2018/8364824 